NASA/TM-2001-209035

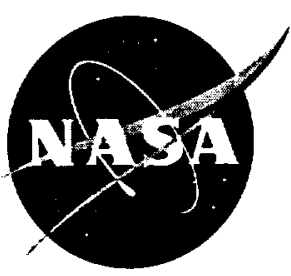

\title{
Development of a Mars Airplane Entry, Descent, and Flight Trajectory
}

James E. Murray

NASA Dryden Flight Research Center

Edwards, California

Paul V. Tartabini

NASA Langley Research Center

Hampton, Virginia






\section{The NASA STI Program Office...in Profile}

Since its founding, NASA has been dedicated to the advancement of aeronautics and space science. The NASA Scientific and Technical Information (STI) Program Office plays a key part in helping NASA maintain this important role.

The NASA STI Program Office is operated by Langley Research Center, the lead center for NASA's scientific and technical information. The NASA STI Program Office provides access to the NASA STI Database, the largest collection of aeronautical and space science STI in the world. The Program Office is also NASA's institutional mechanism for disseminating the results of its research and development activities. These results are published by NASA in the NASA STI Report Series, which includes the following report types:

- TECHNICAL PUBLICATION. Reports of completed research or a major significant phase of research that present the results of NASA programs and include extensive data or theoretical analysis. Includes compilations of significant scientific and technical data and information deemed to be of continuing reference value. NASA's counterpart of peer-reviewed formal professional papers but has less stringent limitations on manuscript length and extent of graphic presentations.

- TECHNICAL MEMORANDUM. Scientific and technical findings that are preliminary or of specialized interest, e.g., quick release reports, working papers, and bibliographies that contain minimal annotation. Does not contain extensive analysis.

- CONTRACTOR REPORT. Scientific and technical findings by NASA-sponsored contractors and grantees.
- CONFERENCE PUBLICATION. Collected papers from scientific and technical conferences, symposia, seminars, or other meetings sponsored or cosponsored by NASA.

- SPECIAL PUBLICATION. Scientific, technical, or historical information from NASA programs, projects, and mission, often concerned with subjects having substantial public interest.

- TECHNICAL TRANSLATION. Englishlanguage translations of foreign scientific and technical material pertinent to NASA's mission.

Specialized services that complement the STI Program Office's diverse offerings include creating custom thesauri, building customized databases, organizing and publishing research results...even providing videos.

For more information about the NASA STI Program Office, see the following:

- Access the NASA STI Program Home Page at http://www.sti.nasa.gov

- E-mail your question via the Internet to help@sti.nasa.gov

- Fax your question to the NASA Access Help Desk at (301) 621-0134

- Telephone the NASA Access Help Desk at (301) 621-0390

- Write to:

NASA Access Help Desk

NASA Center for AeroSpace Information

7121 Standard Drive

Hanover, MD 21076-1320 


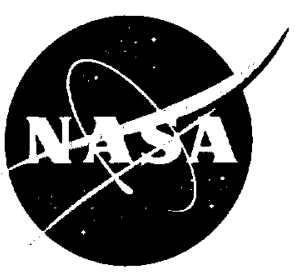

\section{Development of a Mars Airplane Entry, Descent, and Flight Trajectory}

James E. Murray

NASA Dryden Flight Research Center

Edwards, California

Paul V. Tartabini

NASA Langley Research Center

Hampton, Virginia

National Aeronautics and

Space Administration

Dryden Flight Research Center

Edwards, California 93523-(0273

January 2001 


\section{NOTICE}

Use of trade names or names of manufacturers in this document does not constitute an official endorsement of such products or manufacturers, either expressed or implied, by the National Aeronautics and Space Administration.

Available from the following:

NASA Center for AeroSpace Information (CASI)

7121 Standard Drive

Hanover, MD 21076-1320

(301) 621-0390
National Technical Information Service (NTIS) 5285 Port Royal Road Springfield, VA 22161-2171

(703) 487-4650 


\title{
DEVELOPMENT OF A MARS AIRPLANE ENTRY, DESCENT, AND FLIGHT TRAJECTORY
}

\author{
James E. Murray ${ }^{*}$ \\ NASA Dryden Flight Research Center \\ Edwards, California \\ Paul V. Tartabini ${ }^{\dagger}$ \\ NASA Langley Research Center \\ Hampton, Virginia
}

\section{$\underline{\text { Abstract }}$}

An entry, descent, and flight (EDF) trajectory profile for a Mars airplane mission is defined as consisting of the following elements: ballistic entry of an aeroshell; supersonic deployment of a decelerator parachute; subsonic release of a heatshield; release, unfolding, and orientation of an airplane to flight attitude; and execution of a pullup maneuver to achieve trimmed, horizontal flight. Using the Program to Optimize Simulated Trajectories (POST) a trajectory optimization problem was formulated. Model data representative of a specific Mars airplane configuration, current models of the Mars surface topography and atmosphere, and current estimates of the interplanetary trajectory, were incorporated into the analysis. The goal is to develop an EDF trajectory to maximize the surface-relative altitude of the airplane at the end of a pullup maneuver, while subject to the mission design constraints. The trajectory performance was evaluated for three potential mission sites and was found to be site-sensitive. The trajectory performance, examined for sensitivity to a number of design and constraint variables, was found to be most sensitive to airplane mass, aerodynamic performance characteristics, and the pullup Mach constraint. Based on the results of this sensitivity study, an airplane-drag optimized trajectory was developed that showed a significant performance improvement.

*Aerospace Engineer, murray@rigel.dfrc.nasa.gov

Acrospace Engineer, p.v.tartabini@larc.nasa.gov

Copyright $(2001$ by the American Institute of Aeronautics and Astronautics. Inc. No copyright is asserted in the United States under Title 17. U.S. Code. The U.S. Government has a royalty-free license to exercise all rights under the copyright claimed herein for Governmental purposes. All other rights are reserved by the copyright owner

\section{Nomenclature}

\section{Symbols}

$\mathrm{h}_{\mathrm{g}}$

$\mathrm{h}_{\mathrm{AGL}} \quad$ areographic altitude above the Martian surface, $m$ (as defined by MarsGRAM 2000)

$\mathrm{N}$

newton

$\mathrm{Pa} \quad$ pascals

timeo time offset of origin (POST program variable)

$\mathrm{V}_{1} \quad$ inertial velocity, $\mathrm{m} / \mathrm{sec}$

$V_{R} \quad$ velocity relative to the rotating planet (Mars), $\mathrm{m} / \mathrm{sec}$

$\gamma_{I R V} \quad$ flightpath angle relative to the plane that is perpendicular to the areocentric radius vector, deg (fig. 3)

$\gamma_{R} \quad$ flightpath angle relative to the rotating planet local vertical and local horizontal frame, deg

$\theta$

entry interface direction angle, deg (fig. 4)

\section{Subscripts}

$\mathrm{e}$

start of the trajectory (entry interface)

f

end of trajectory (airplane first reaches horizontal flight)

\section{Acronyms}

$\begin{array}{ll}\text { AP } & \text { Acidalia Planitia } \\ \text { DGB } & \text { disk-gap-band }\end{array}$




$\begin{array}{ll}\text { DOF } & \text { degree-of-freedom } \\ \text { EDF } & \text { entry, descent, and flight } \\ \text { GMT } & \text { Greenwich Mean Time } \\ \text { HP } & \text { Hellas Planitia } \\ \text { MCI } & \text { Mars-centered inertial } \\ \text { MG2K } & \text { MarsGRAM 2000 (Mars Global Reference } \\ & \text { Atmospheric Model) } \\ \text { POST } & \begin{array}{c}\text { Program to Optimize Simulated } \\ \text { Trajectories }\end{array} \\ \text { PV } & \text { Parana Valles } \\ & \text { Introduction }\end{array}$

The possibility of heavier-than-atmosphere flight on the planet Mars has intrigued scientists and engineers for decades. The Mini-Sniffer, designed, built, and flown at the NASA Dryden Flight Research Center (Edwards, California) in the $1970 \mathrm{~s},{ }^{1}$ was one of the earliest aircraft designed for flight in the Martian atmosphere. Follow-on studies ${ }^{2-3}$ evolved from airframe and propulsion concepts to complete mission concepts, including delivery of the aircraft to Mars, planetary entry and aircraft deployment. Subsequent advances in solar-cell efficiency and lightweight aerospace structures allowed the consideration of solarelectric propulsion systems ${ }^{4}$ and large, lightly-loaded structures ${ }^{5-6}$ for the Mars airplane mission. In recent years, the trend toward smaller, lighter spacecraft has strongly influenced Mars airplane design work, and interest in a Mars airplane flight mission has heightened. A number of published ${ }^{7}$ and unpublished airplane and mission designs has resulted.

In early 1999, NASA initiated a study of the feasibility of conducting a Mars airplane flight on December 17, 2003 to commemorate the 100th anniversary of the Wright brothers first powered flight. For this mission, the airplane would be carried to the planet stowed inside a small aeroshell that would be attached to a carrier spacecraft. Upon reaching Mars, the aeroshell would be released for direct entry into the Martian atmosphere. After atmospheric deceleration, the aeroshell would release the airplane for a subsonic atmospheric flight mission.

Design efforts were initiated at several NASA centers, and a number of Mars airplane designs evolved. ${ }^{8}$ At the Langley Research Center, one element of the initial design effort was the development of a baseline entry, descent, and flight (EDF) trajectory to effect the transition from hypersonic, ballistic aeroshell flight to subsonic lifting airplane flight. The development of a baseline EDF trajectory was important early in the design cycle to bound the airplane deployment and flight envelope, to identify high-level trends, to identify potential "showstopper" scenarios, and to provide early

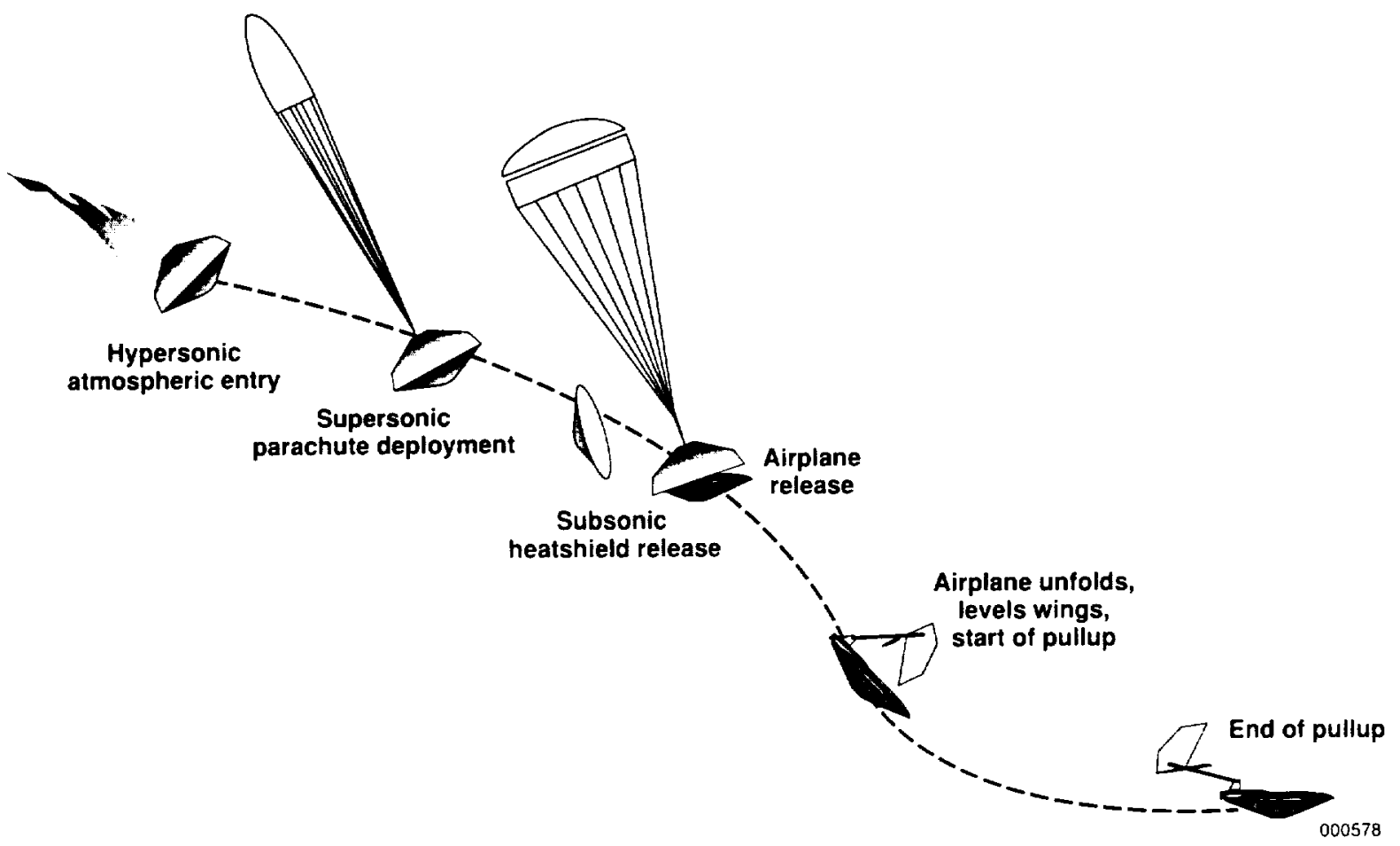

Figure 1. Schematic of the baseline entry, descent, and flight trajectory. 
feedback to other design disciplines. For initial design purposes a baseline EDF trajectory profile (fig. 1) was defined as consisting of the following elements: ballistic, hypersonic entry of the aeroshell; supersonic deployment of a decelerator parachute; subsonic release of the heatshield; release, unfolding, and orientation of the airplane to flight attitude; and execution of a pullup maneuver to achieve trimmed, horizontal flight.

A baseline EDF trajectory was developed with a classical trajectory optimization approach, using the industry standard, the Program to Optimize Simulated Trajectories (POST) ${ }^{9}$ Model data for the specific Mars airplane configuration studied current models of the Mars atmosphere and surface topography, and current estimates of the interplanetary trajectory were supplied to this analysis by other members of the design team. Heritage elements from previous and current planetary missions were used where feasible. However, the atmospheric flight portion of the Mars Airplane Mission is unprecedented in planetary exploration and requires significant mission-specific design and development.

This paper documents the initial EDF trajectory development for a Mars airplane configuration developed at the Langley Research Center. A description of the configuration studied and a definition of that subset of the mission that was considered in the EDF analysis is included. The formulation of the trajectory optimization problem is presented in detail. The configuration-specific data used to model the aeroshell, the decelerator parachute, and the airplane are presented. The source and implementation of the Mars atmospheric and topographic models are also included. The interface between the supplied interplanetary trajectory and EDF analysis is presented, and the underlying assumptions and limitations of the analysis are discussed.

Three potential mission sites on the planet were evaluated in this analysis. The baseline optimal trajectory for each site is presented in detail. Sensitivity of one of the baseline trajectories to a suite of parametric variations is also evaluated and presented in detail. The sensitivity analyses suggest modifications to the baseline EDF trajectory design that show potential for significant performance improvement. One of these design modifications was studied further and that resulting airplane-drag optimized trajectory design is presented. Note that use of trade names or names of manufacturers in this document does not constitute an official endorsement of such products or manufacturers, either expressed or implied. by the National Aeronautics and Space Administration.

\section{Analytical Framework}

\section{Configuration Description}

The configuration studied consists of three primary elements: an entry aeroshell, a decelerator parachute for the aeroshell, and a foldable airplane. Dimensioned drawings of each element are shown in figure 2 . The aeroshell is an axis-symmetric, ballistic design similar in geometry to aeroshells used in previous Mars missions, ${ }^{10}$ with a releasable heatshield. In the initial phase of planetary entry, the heatshield is attached (as shown in fig. 2(a)) and both the decelerator parachute and the folded airplane are contained within the outer mold line of the aeroshell. The parachute is a disk-gapband (DGB) ${ }^{11}$ design similar to that used on the Mars Pathfinder mission. ${ }^{14}$

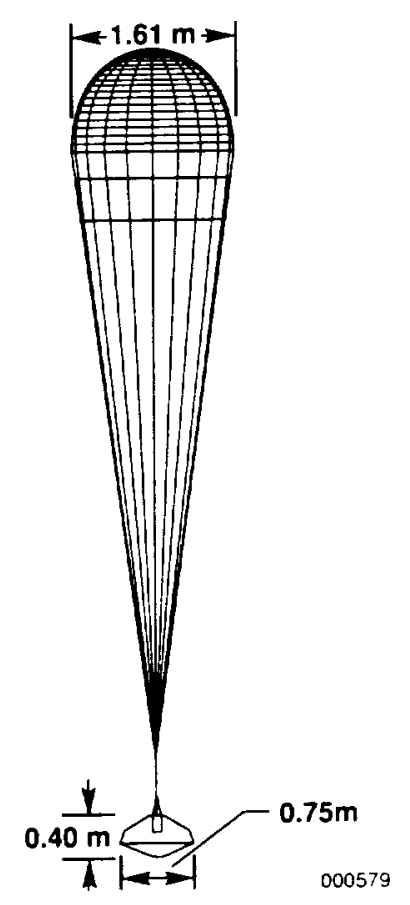

(a) Aeroshell and parachute.

Figure 2. Dimensioned drawings of the aeroshell. parachute, and airplane used in the EDF analysis.

The airplane is designed with 4 hinge lines that allow it to be folded for containment within the aeroshell; one hinge line where each wing outboard panel meets the body, one hinge line where the twin tailbooms meet the body, and one hinge line where the vertical tail meets the horizontal tail. Figure 2(b) shows the airplane in its unfolded. flight configuration. 


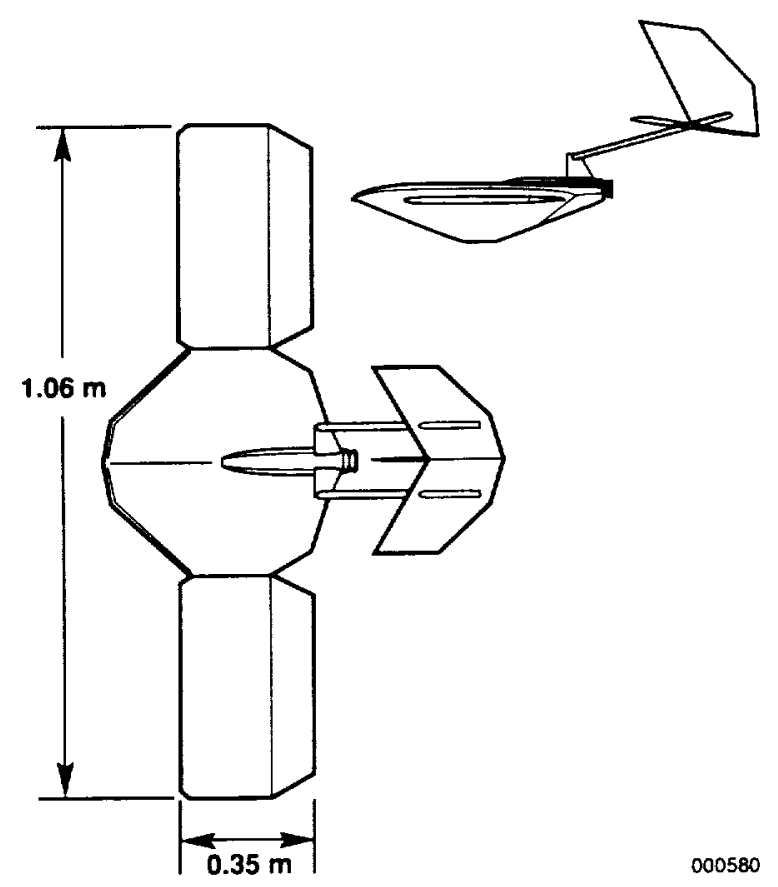

(b) Airplane.

Figure 2. Concluded.

\section{Coordinate Systems}

The analysis and the presentation of results use several different coordinate systems. Figures 3 and 4 present elements of these coordinate systems that are pertinent to this paper. The Mars reference surface (fig. 3) is a biaxial ellipsoid. Areocentric radius (fig. 3) is the radial distance from the center of Mars, and the inertial flightpath angle, $\gamma_{1 R V}$, (fig. 3) is measured relative to the plane that is perpendicular to the

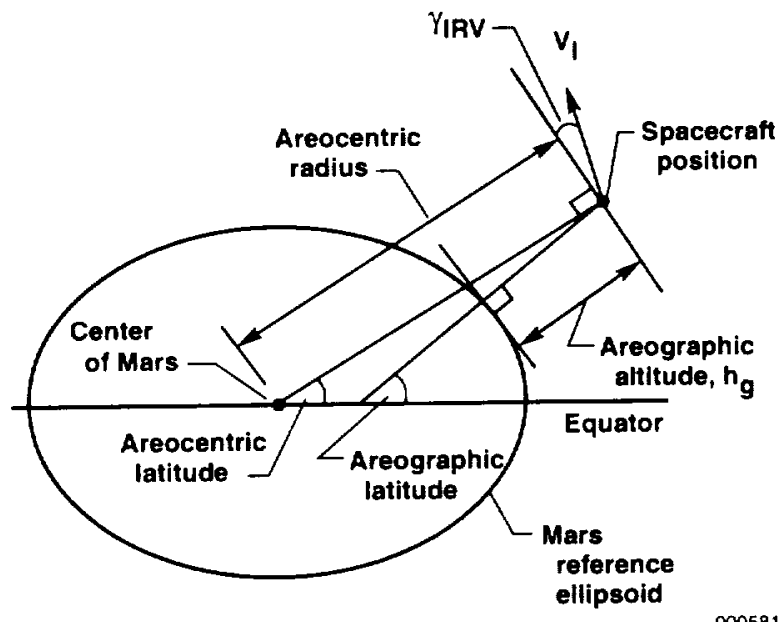

Figure 3. Planetary geometry and trajectory parameter definitions.

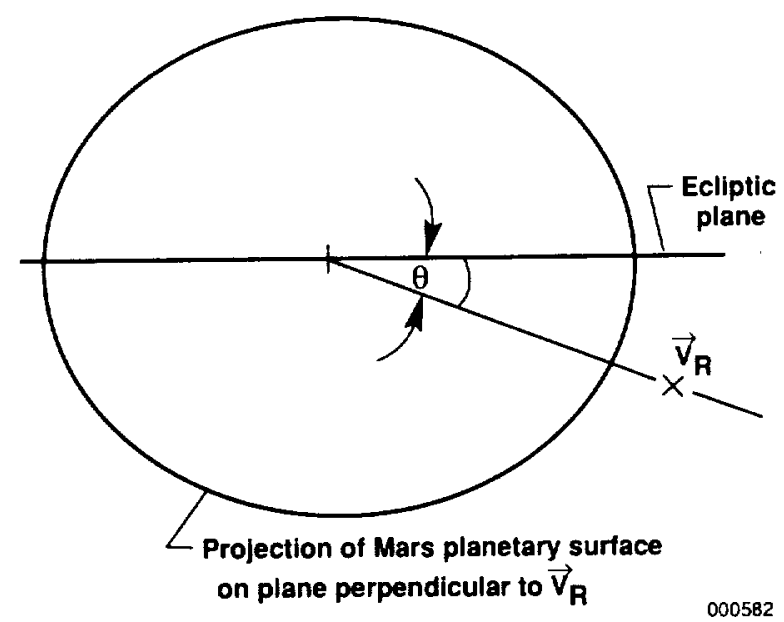

Figure 4. Definition of entry interface direction angle, $\theta$.

areocentric radius vector. Areographic altitude, $h_{g}$, (fig. 3) is measured relative to the plane that is tangent to the planetary reference ellipsoid. Surface-relative areographic altitude, $h_{A G L}$, (fig. 3 ) is measured relative to local surface topography. The entry interface direction angle, $\theta$, is measured clockwise from the ecliptic plane to the spacecraft trajectory plane, projected on the plane perpendicular to the spacecraft relative velocity vector (fig. 4$).^{12}$

\section{EDF Trajectory Overview}

A schematic of the baseline EDF trajectory sequence is shown in figure 1. For this analysis, the EDF trajectory begins when the aeroshell enters the Martian atmosphere at an areocentric radius of $3527.20 \mathrm{~km}$ and a Mars-centered inertial (MCI) velocity of approximately $5.6 \mathrm{~km} / \mathrm{sec}^{13}$ During entry, the aeroshell is spin-stabilized and performs a ballistic entry and deceleration through the upper atmosphere. After entry, planet-relative velocity, $V_{R}$, and planet-relative flightpath angle, $\gamma_{R}$. are used because they become more meaningful than their inertial counterparts. At supersonic speed, the aeroshell deploys a DGB parachute to further decelerate the aeroshell. At subsonic speed, the heatshield is released from the backshell, and after further deceleration of the system. the folded airplane is released from the backshell. At this point in the trajectory the system still has a significant downrange velocity component and $\gamma_{R}$ has not yet become vertical. Now in free flight, the airplane unfolds its wings and tail surfaces and performs an orientation maneuver to roll wings-level. The airplane performs a pitch-up to an angle of attack corresponding 
to a high lift coefficient and begins to pull up from its steep $\gamma_{R}$. The airplane accelerates as it descends, the Mach number peaks and begins to drop near the end of the pullup maneuver; the EDF trajectory ends when the airplane reaches level fight (that is, $\gamma_{R}=0$ ).

\section{Objectives}

The fundamental performance metric for the EDF trajectory design was the areographic altitude above the Martian surface at the end of the EDF trajectory,

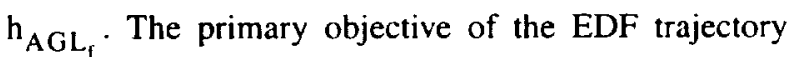
development was to design a baseline trajectory that maximizes $h_{A G L_{f}}$, while subject to the mission design constraints. A second objective was to evaluate the sensitivity of $h_{A_{G L}}$ to model parameter variations. Based on the results of the sensitivity study, a third objective was to develop a second-generation EDF trajectory design which was additionally optimized for airplane drag.

\section{Approach}

Trajectory optimization was performed using the three-degrees-of-freedom (DOF) (translational) version of the Program to Optimize Simulated Trajectories (POST), ${ }^{9}$ an industry standard trajectory design and analysis tool. As a trajectory optimization tool, POST integrates the equations of motion defined by user-supplied model data while solving a constrained optimization problem. Starting with an initial usersupplied optimal control vector guess, POST iteratively searches for the optimal control vector that maximizes a scalar objective function while subject to user-defined constraints. The output of a POST optimization run is the optimal control vector and its corresponding trajectory time history. Further details on the structure and algorithms used in POST can be found in reference 9.

For the EDF trajectory, the optimization problem is defined as:

Find the optimal control vector defined by

- $\theta$

- $\gamma_{1 R V_{e}}$

- Time of entry interface relative to zero-hour Greenwich Mean Time (GMT) on December 17. 2003

- Time of aeroshell parachute deployment, relative to time of entry interface

- Mach number at heatshield release
- Time of airplane release from aeroshell, relative to time of heatshield release

this maximizes the objective function

$\mathrm{h}_{\mathrm{AGL}}$

while subject to the constraints

$-22^{\circ} \leq \gamma_{\mathrm{IRV}} \leq-12^{\circ}$

- $1.6 \leq$ Mach number at aeroshell parachute deployment $\leq 2.28$

- $400 \mathrm{~Pa} \leq$ dynamic pressure at aeroshell parachute deployment $\leq 1175 \mathrm{~Pa}$

- Mach number at heatshield release $\leq 0.9$

- Maximum deceleration during entire trajectory $\leq 20$ Earth $g$

- Maximum Mach number achieved during airplane pullup maneuver $\leq 0.8$

- Site areocentric latitude

- Site longitude

Where possible, heritage design elements from previous and current Mars missions were used to guide the specification of the trajectory design constraints. The $\gamma_{I R V_{e}}$ constraint was based on experience gained through a number of Mars entry designs. The aeroshell parachute deployment constraints (defined by the Mach number and dynamic pressure) are identical to the parachute deployment constraints used by the Mars Surveyor 2001 lander. $^{14}$ The heatshield release constraint and the maximum deceleration constraint were based on engineering judgment. No heritage design elements were available to guide the selection of the maximum Mach number allowed during the airplane pullup maneuver; therefore engineering judgment was used to select a constraint value intended to preclude shock-induced surface buzz and flutter.

\section{$\underline{\text { Limitations }}$}

Several fundamental limitations of this analysis merit discussion. For all phases of the trajectory, only the three-DOF (translational) system of equations was implemented. No guidance or control laws were implemented, and perfect sensing of the trajectory state was assumed for all trajectory decisional logic. Atmospheric winds were not modeled. No constraints based on entry aerodynamic heating were implemented. At the time of the analysis, some model data were 
immature and were implemented as the current best estimates.

\section{$\underline{\text { Models }}$}

Model data for each phase of the trajectory are required in order to define the dynamic models used by POST. The model data came from a variety of sources. The model data, their sources, and their implementation within POST are described below.

\section{Planet. Atmosphere, and Surface Topography Model}

The planet reference surface is modeled as a biaxial ellipsoid in POST, as shown in figure 3. The Mars atmosphere and surface topography models are supplied to POST by MG2K, an updated version of the original MarsGRAM. ${ }^{15}$ The MarsGRAM 2000 is implemented as a subroutine called from POST. Along the computed trajectory, POST passes the appropriate trajectory state variables (areocentric latitude, longitude, areocentric altitude, time of day, and Julian date) to MG2K. MarsGRAM 2000 returns the atmosphere state variables (temperature, pressure, and density), the surface elevation, and several subsidiary variables to POST. This approach gives POST all the information necessary to compute the air-relative state vector for the airplane for any location on the planet at any time; all spatial, seasonal, and diurnal atmospheric variations modeled by $\mathrm{MG} 2 \mathrm{~K}$ are made available to the analysis.

\section{Entry Interface State Vector}

The interplanetary flight trajectory constrains the range of available entry interface states, and thus the range of sites on the planet accessible to the mission. Entry interface was defined at an areocentric radius of $3527.20 \mathrm{~km}$, and the range of available entry interface state vectors was provided by reference 3 . The entry interface state vector ( 3 position components, 3 velocity components) was supplied as a function of two independent variables: the entry interface direction angle, $\theta$. and the entry interface inertial flightpath angle, $\gamma_{I R V_{s}}$. The entry interface direction (or "clock") angle. $\theta$, is defined in figure 4 , and $\gamma_{I R V_{r}}$ is defined in figure $3{ }^{9}$ The entry interface cartesian state vector was supplied in the Mars-centered inertial (MCI) system of December 17. 2003, zero-hour GMT for a $\theta, \gamma_{I R V_{e}}$ matrix defined by

$$
\begin{aligned}
& -100^{\circ} \leq \theta \leq 70^{\circ} \\
& -24^{\circ} \leq \gamma_{\mathrm{IRV}} \leq-12^{\circ}
\end{aligned}
$$

For illustration purposes, the $\theta, \gamma_{I R V_{e}}$ coordinate system can be converted (internally by POST) to the areocentric latitude and longitude coordinate system. Figure 5 shows the transformation of the $\theta, \gamma_{I R V_{e}}$ matrix supplied by Paul Penzo ${ }^{11}$ into the equivalent areocentric latitude, longitude matrix.

For entry interface times other than the specified zerohour GMT, the entry interface areocentric latitude remains unchanged, but the entry interface longitude changes owing to the rotational velocity of Mars. An entry after zero-hour GMT would be further west; an entry prior to zero-hour GMT would be further east. By allowing the entry interface time to be offset from zero-hour GMT, nearly the complete planet is made accessible to the analysis. Entry time offset relative to zero-hour GMT is modeled by the internal POST variable timeo. Thus, within POST, the entry interface state is completely specified by three independent variables: $\theta, \gamma_{1 R V_{e}}$, and timeo. This approach allows the analysis access to all sites available on the planet.

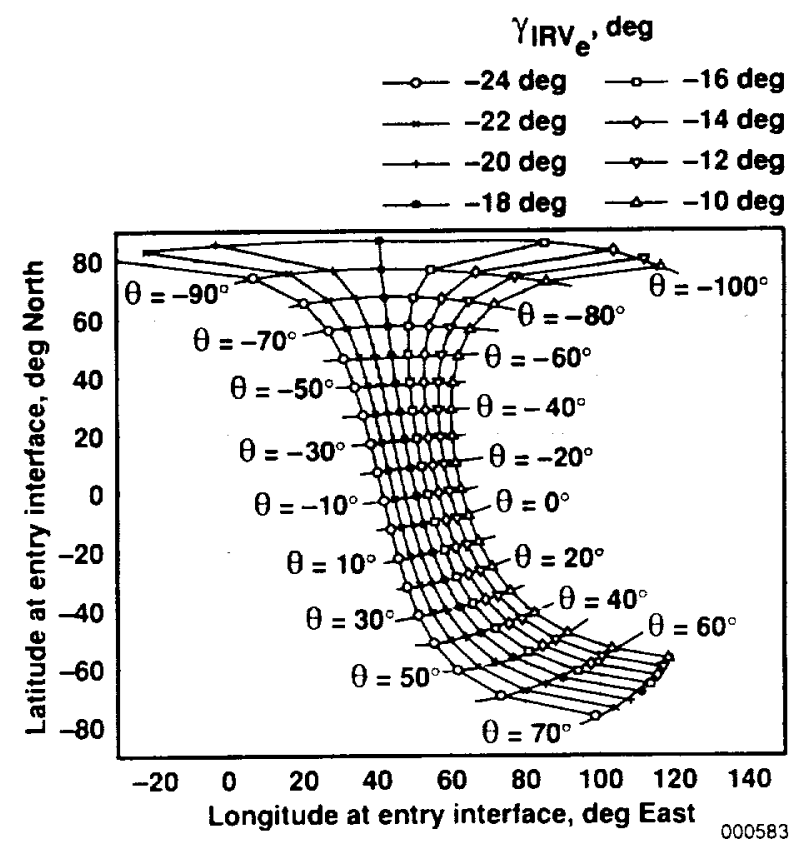

Figure 5. Entry interface areocentric latitude as a function of entry interface longitude for entry at zerohour GMT December 17, 2003. 


\section{Mass Properties}

The mass of the complete system at entry (backshell, heatshield, parachute assembly, and airplane) is $40 \mathrm{~kg}$. The mass of the heatshield, based on preliminary design work, is $3.6 \mathrm{~kg}$. Mass lost as a result of ablation of the heatshield is not modeled. The mass of the airplane alone is $18.0 \mathrm{~kg}$.

\section{Aerodynamics}

The aerodynamic model for the aeroshell included only drag coefficient and was the same as the aerodynamic model used for the Mars 2001 lander. $^{14}$ The parachute used in this analysis was based on scaling the parachute used in the Mars Pathfinder mission, assuming an equal packing density. The inflated diameter of the aeroshell parachute is $1.61 \mathrm{~m}$, and the reference diameter for the aeroshell parachute is $2.53 \mathrm{~m}$. The aeroshell parachute aerodynamic model was adapted from the Mars Pathfinder project work. For this analysis, the model consists of three parts: the basic drag coefficient, ${ }^{10}$ one scale factor as a function of Mach number, ${ }^{16}$ and a second scale factor as a function of deployment time (parachute inflation dynamics). The drag coefficient used by POST is the product of all three.

The airplane aerodynamic model was developed using a combination of computational fluid dynamics codes, wind tunnel tests, and engineering judgment. The resulting aerodynamic model lift and drag coefficients were a function of flight condition (Mach number, unit Reynolds number), control surface deffection, and angle of attack. Because the EDF analysis used only the 3DOF (translational) equations of motion, aircraft pitch dynamics were not modeled. Thus, the dependency on control surface deflection and angle of attack was removed, and only the dependency on flight condition was retained, resulting in lift and drag coefficients as two-dimensional tables of Mach number and unit Reynolds number. The lift coefficient value at each table entry was the maximum usable lift coefficient $(90$ percent of the maximum trimmed lift coefficient) at the corresponding flight condition (Mach number, unit Reynolds number), and is shown in figure 6. This lift coefficient value was selected to provide high lift during the pullup maneuver, while still giving a measure of stall margin. The drag coefficient value at each table entry was the drag coefficient at the maximum usable lift coefficient, and is shown in figure 7 .

For the flight envelope considered, both the lift and drag coefficients are strong functions of both Mach number and unit Reynolds number; there is a steep rise

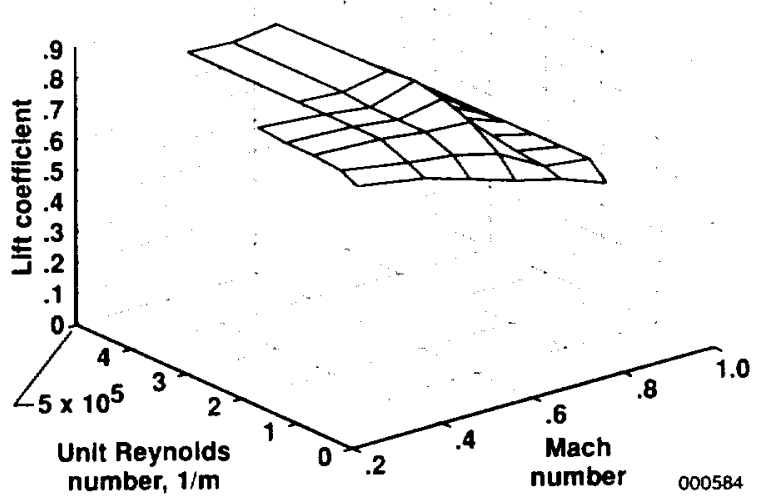

Figure 6. Airplane lift coefficient model.

in drag coefficient and a drop in lift coefficient at the increased Mach numbers and reduced unit Reynolds numbers. Mach number and unit Reynolds number are functions of atmospheric state variables as well as true airspeed. For the wide variation in atmospheric conditions on the planetary scale considered in the analysis, a wide variation in flight Mach number and Reynolds number is possible, even at the same true airspeed flight condition.

Based on engineering judgment, the time required for the airplane to unfold from its stowed configuration was set to $1.0 \mathrm{sec}$, and the time required for the airplane to maneuver to a wings-level attitude in preparation for executing the pullup maneuver was set at $5.0 \mathrm{sec}$. During airplane unfolding and orientation, the airplane is modeled as having zero lift coefficient and the drag coefficient shown in figure 7. During the pullup maneuver, the airplane is modeled as having the lift coefficient shown in figure 6 and the drag coefficient

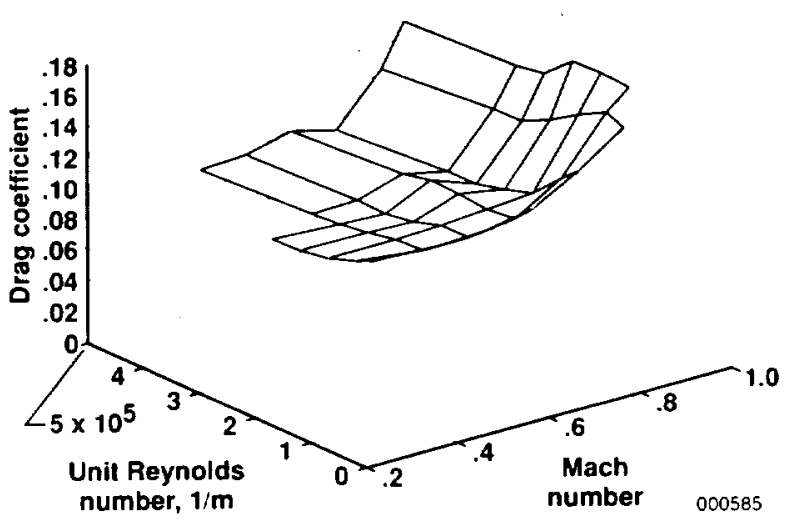

Figure 7. Airplane drag coefficient model. 
shown in figure 7. The lift coefficient makes an abrupt (step) transition between the orientation maneuver and the pullup maneuver.

\section{Results of the Baseline Trajectories}

Three potential mission sites were studied in this analysis: Parana Valles (PV) at approximately $25^{\circ} \mathrm{S}$ and $11^{\circ} \mathrm{W}$, Acidalia Planitia (AP) at approximately $55^{\circ} \mathrm{N}$ and $27^{\circ} \mathrm{W}$, and Hellas Planitia (HP) at approximately $38^{\circ} \mathrm{S}$ and $63^{\circ} \mathrm{E}$. In the context of this analysis, the site latitude and longitude are those values at the end of the trajectory. The PV site was selected for its value to the scientific community. The AP and the HP sites were identified through a planetwide search for a global maximum of $h_{A G L}$. The existence of a number of local terrain features with low site topography (for example, impact basins, craters) makes such a planetwide search sensitive to the initial value of the control vector (specifically $\theta, \gamma_{1 R V_{e}}$, and timeo) used in the analysis. and susceptible to convergence to a local maximum rather than the global maximum. Hence, a wide range of initial values was used, guided by an existing topographical map of the planet. ${ }^{17}$ In the Northern Hemisphere, the search was conducted for all longitudes and latitudes between $35^{\circ} \mathrm{N}$ and $55^{\circ} \mathrm{N}$, and yielded two local maxima; the largest local maximum found was the AP site. The Southern Hemisphere was searched only within the Hellas basin, the dominant depression in that hemisphere. Two local maxima were identified within the Hellas basin and the best site was selected.

Figures 8 through 11 show time histories of the EDF trajectory for these three mission sites. On each figure, the symbols denote the points along the trajectory where significant mission events occur. The trajectories for the three sites show a number of similarities. Each trajectory starts at an $\gamma_{\mathrm{R}_{\mathrm{e}}}$ near $-22^{\circ}$ (fig. 8), the lower boundary on the $\gamma_{R_{e}}$ constraint. The trajectory Mach number (fig. 9), $h_{g}$ (fig. 10), and dynamic pressure (fig. 11) profiles during the hypersonic and supersonic flight regimes are largely a function of $\gamma_{R_{e}}$, and are similar in profile. Some site-specific differences are evident, however. The value of $\gamma_{R}$ at the start of the pullup maneuver (fig. 8) varies among the sites, the time required to execute the pullup maneuver also is shorter for the AP site than for the other two sites.

Figures 12 through 18 show a detailed view of the pullup maneuver for each of the three trajectories. Note that the time scales have been shifted so that they start with initiation of the pullup maneuver. The trajectories for the HP and PV sites are similar and the AP site is significantly different. Most notably, even though the pullup maneuver starts at a steeper $\gamma_{R}$ for the AP site, the pullup maneuver for the AP site takes significantly less time (fig. 12), and thus achieves less net altitude loss during the pullup maneuver (fig. 14) as compared to the HP and PV sites. The pullup maneuver at the AP site is executed with less net altitude loss largely because of its increased lift during the pullup maneuver (fig. 15); increased lift rotates the velocity vector more quickly toward $\gamma_{R}=0$. The higher lift is largely a result of improved airfoil lift performance at the increased Reynolds numbers achieved at the AP site (fig. 16); the increased Reynolds numbers are largely caused by reduced temperature and resulting reduced kinematic viscosity (fig. 17) at this Northern Hemisphere site.

While figure 14 presents the altitude with respect to the Mars reference ellipsoid, $h_{g}$, figure 18 presents the altitude with respect to the Mars local surface, $h_{A G L}$. The relatively low surface topography at both the AP and the HP sites yield $h_{A G L_{f}}$ values in excess of $2000 \mathrm{~m}$. The relatively elevated surface topography at the PV site yields a negative value for $h_{A G L_{f}}$; the trajectory at the PV impacts the Mars surface before completing the pullup maneuver.

Summary information for the three potential mission sites studied is presented in table 1 .

Table 1. Summary characteristics of three potential mission sites.

\begin{tabular}{lcc}
\hline \multicolumn{1}{c}{ Mission site } & $\mathrm{h}_{\mathrm{g}_{\mathrm{f}}, \mathrm{m}}$ & $\mathrm{h}_{\mathrm{AGL}_{1}, \mathrm{~m}}$ \\
\hline Acidalia Planitia & 263 & 2745 \\
Hellas Planitia & 420 & 2327 \\
Parana Valles & 549 & -1803 \\
\hline
\end{tabular}




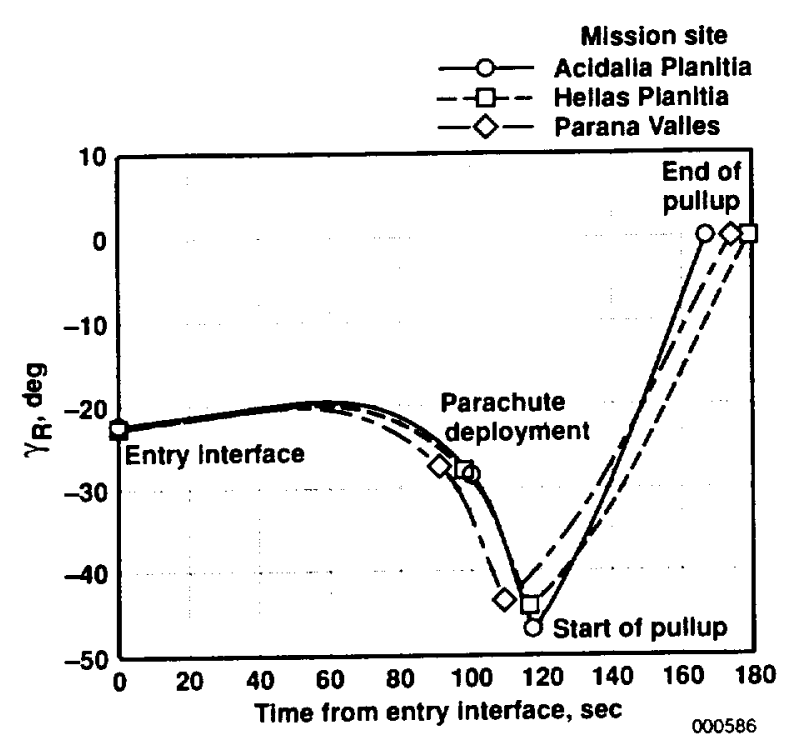

Figure 8. Time history of $\Upsilon_{R}$ for the trajectory for three mission sites.

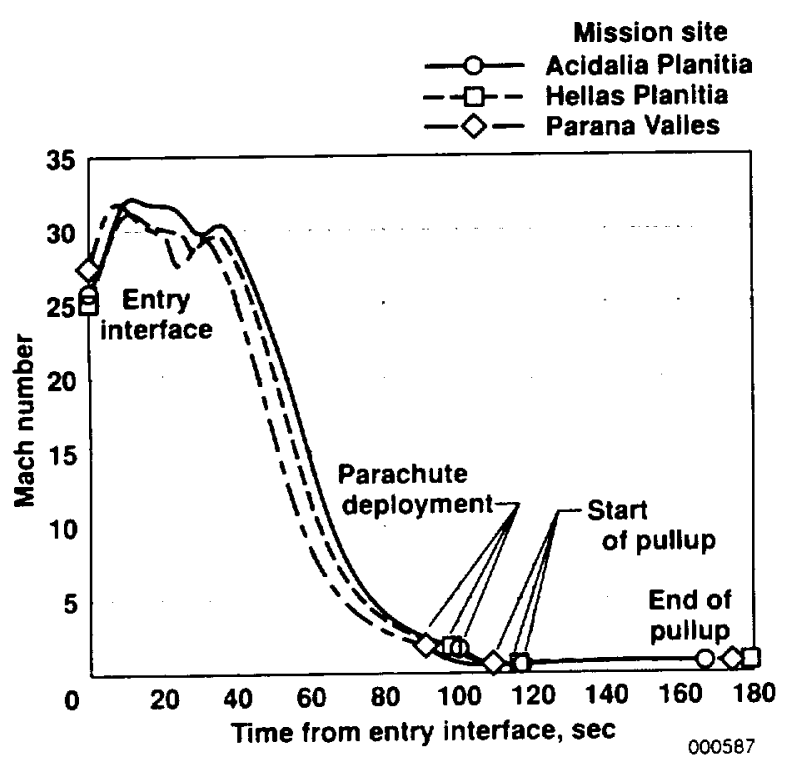

Figure 9. Time history of Mach number for the trajectory for three mission sites.

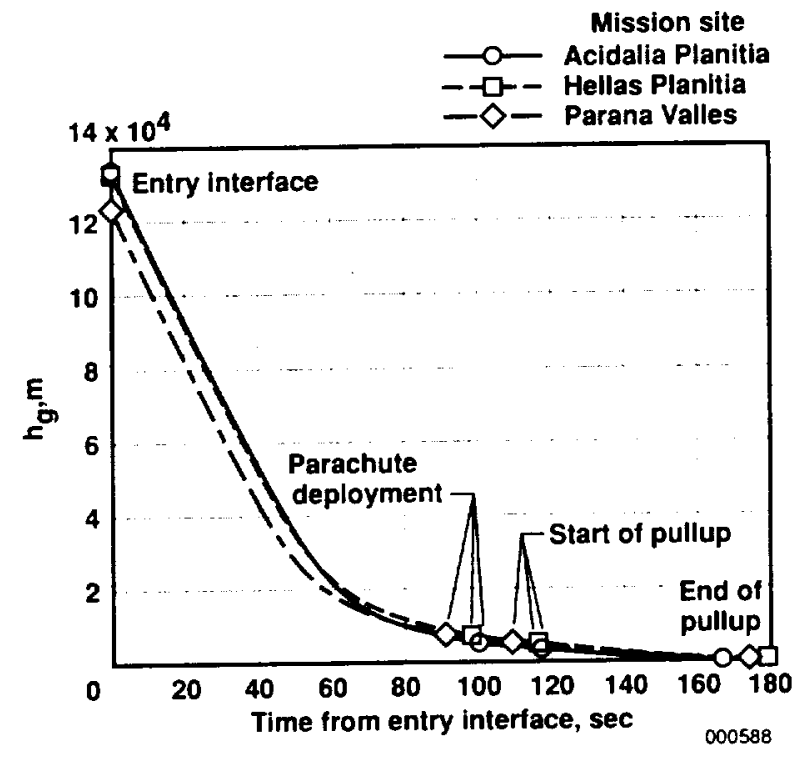

Figure 10. Time history of $\mathrm{h}_{\mathrm{g}}$ for the trajectory for three mission sites.

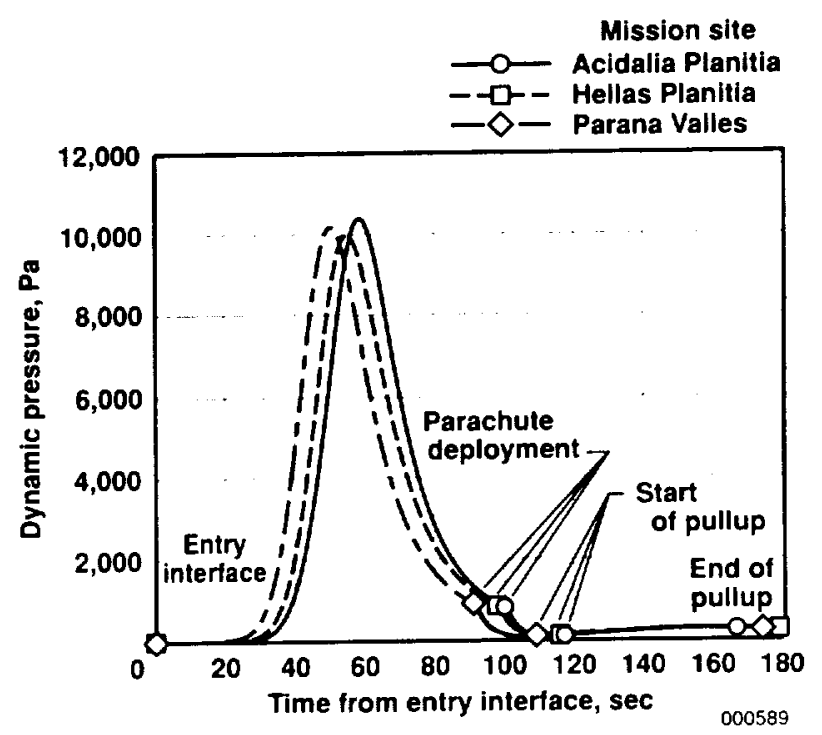

Figure 11. Time history of dynamic pressure for the trajectory for three mission sites. 


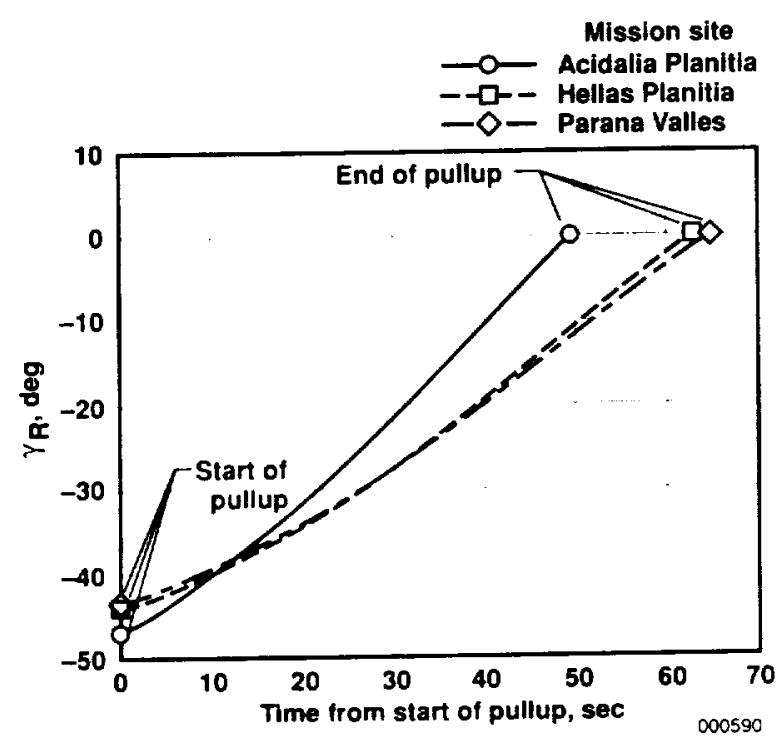

Figure 12. Time history of $\vec{l}_{R}$ during pullup maneuver.

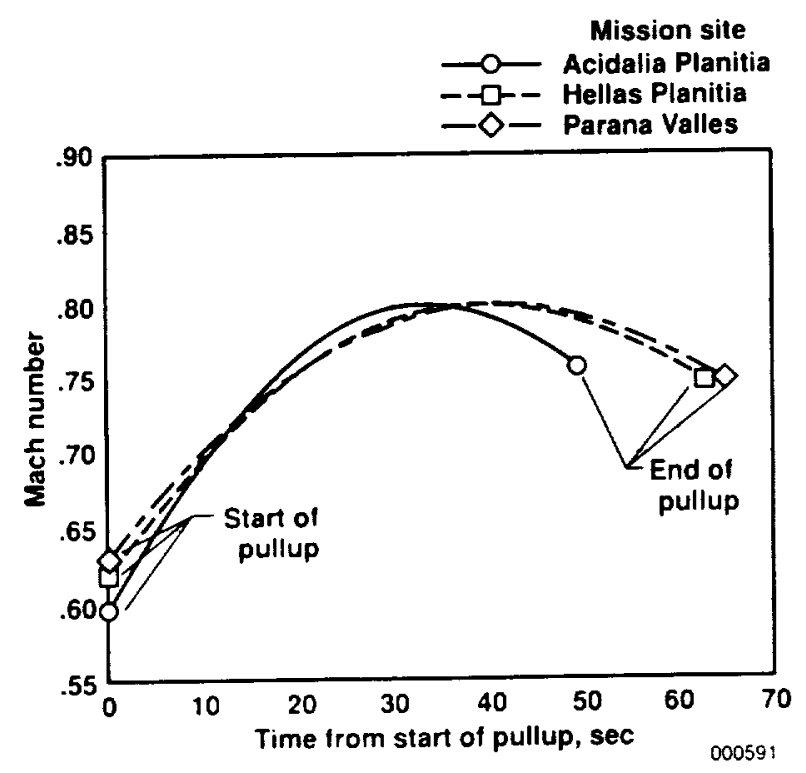

Figure 13. Time history of Mach number during pullup maneuver.

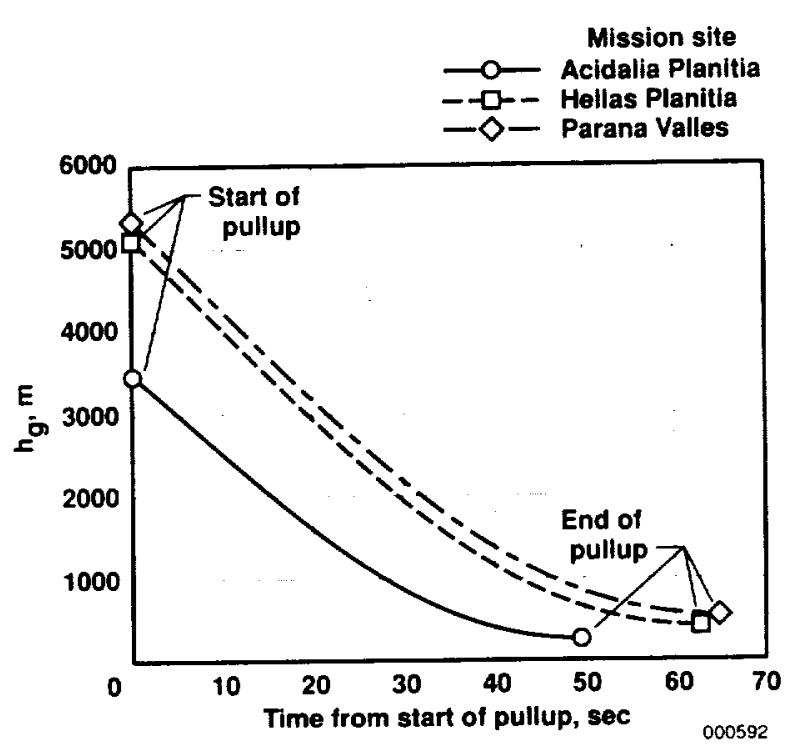

Figure 14. Time history of $\mathrm{h}_{\mathrm{g}}$ during pullup maneuver.

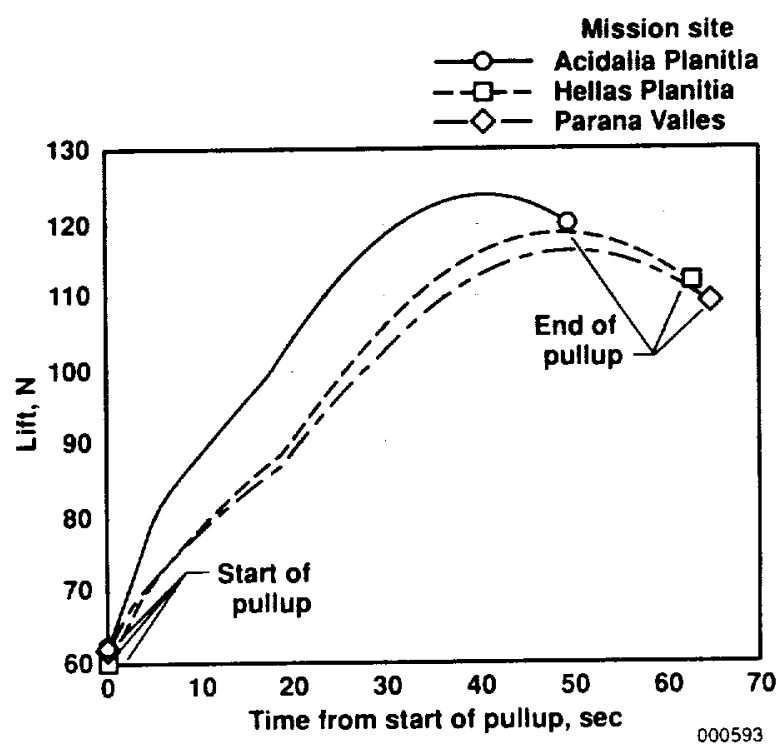

Figure 15. Time history of airplane lift during pullup maneuver. 


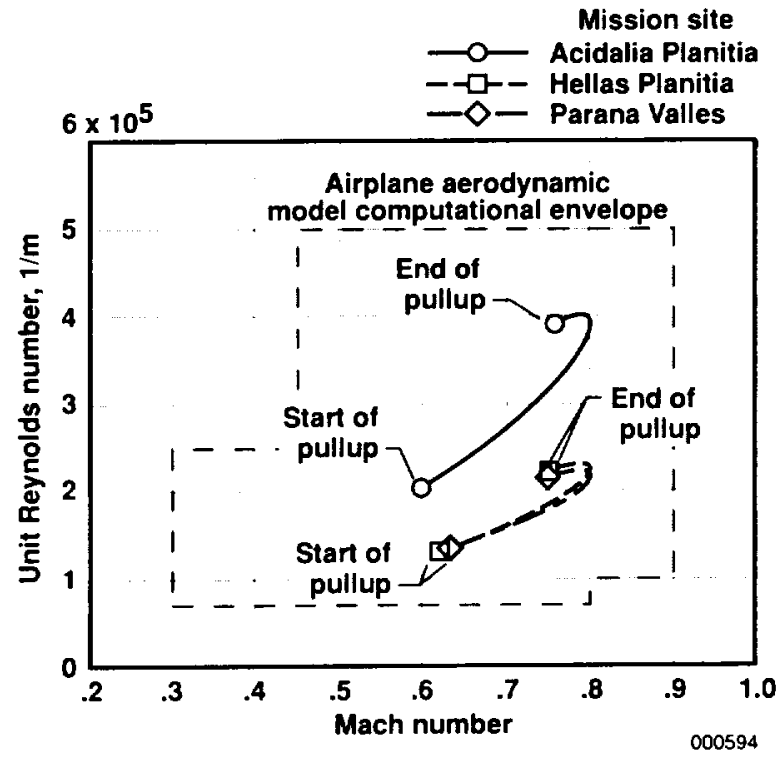

Figure 16. Unit Reynolds number as a function of Mach number during pullup maneuver.

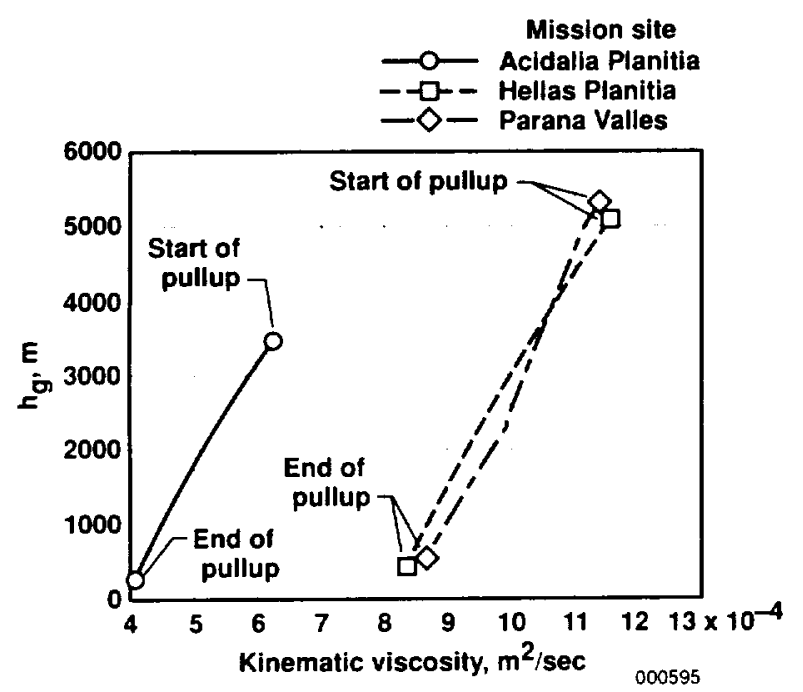

Figure 17. Kinematic viscosity as a function of $h_{g}$ during pullup maneuver.

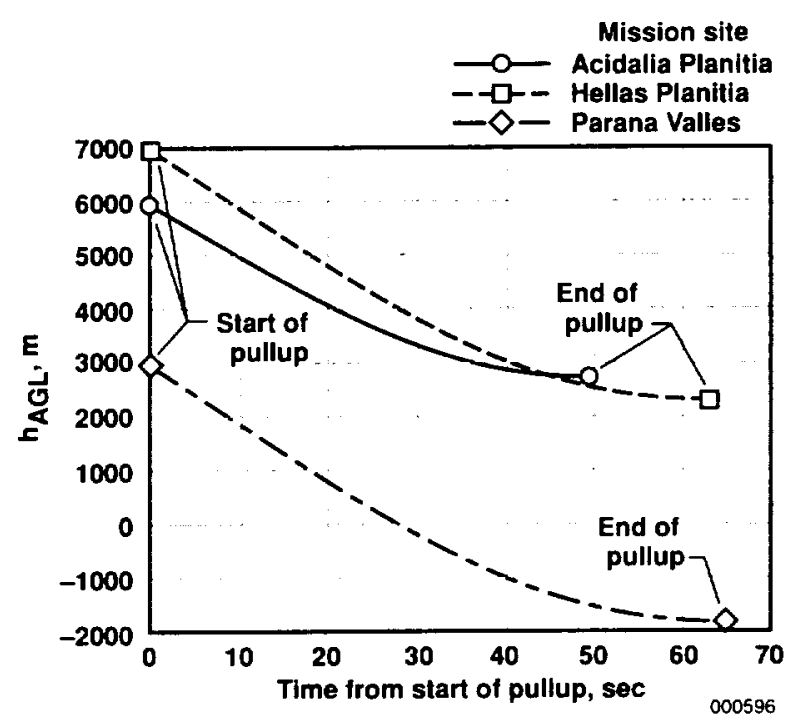

Figure 18. Time history of $\mathrm{h}_{\mathrm{AGL}}$ during pullup maneuver.

\section{Parametric Sensitivity Analysis}

In addition to finding the baseline trajectory associated with the nominal model data sets, the trajectory sensitivity to perturbations in the model data and constraint values was examined. A simple parametric sensitivity analysis was conducted for the Acidalia Planitia site. Starting with the baseline model data, each of a selected number of model parameters and constraint values was perturbed from its nominal value. and POST was used to find the solution to the new trajectory optimization problem. Each parameter was perturbed by 5 percent in each direction. Table 2 shows the results of the parameter sensitivity analysis, arranged in order of decreasing sensitivity.

Several results are noteworthy. The value of $h_{A G L}$ is most sensitive to the pullup Mach constraint, the airplane mass, and the airplane lift coefficient. Increasing the lift coefficient, raising the Mach constraint value, and decreasing the airplane mass all yield improved pullup performance and higher $h_{A G L}$. While the sensitivity to lift coefficient and airplane mass perturbations is approximately symmetric in the range 
Table 2. Parametric sensitivity study results for Acidalia Planitia site.

\begin{tabular}{|c|c|c|c|c|c|}
\hline Parameter name & $\begin{array}{c}\text { Nominal } \\
\text { value }\end{array}$ & $\begin{array}{c}1.05 \times \\
\text { nominal } \\
\text { value }\end{array}$ & $\begin{array}{l}\text { Change in } \\
h_{\mathrm{AGL}_{\mathrm{f}}}, \mathrm{m}\end{array}$ & $\begin{array}{c}0.95 \times \\
\text { nominal } \\
\text { value }\end{array}$ & $\begin{array}{l}\text { Change in } \\
\mathrm{h}_{\mathrm{AGL}_{\mathrm{f}}}, \mathrm{m}\end{array}$ \\
\hline Airplane Mach constraint & 0.8 & 0.84 & +771 & 0.76 & -3517 \\
\hline Airplane mass & $18.0 \mathrm{~kg}$ & $18.9 \mathrm{~kg}$ & -611 & $17.1 \mathrm{~kg}$ & +561 \\
\hline Airplane lift coefficient multiplier & 1.0 & 1.05 & +436 & 0.95 & -451 \\
\hline Airplane drag coefficient multiplier & 1.0 & 1.05 & +119 & 0.95 & -105 \\
\hline Entry mass & $40.0 \mathrm{~kg}$ & $42.0 \mathrm{~kg}$ & +89 & $38.0 \mathrm{~kg}$ & -222 \\
\hline Airplane orientation time & $5.0 \mathrm{sec}$ & $5.25 \mathrm{sec}$ & -55 & $4.75 \mathrm{sec}$ & +61 \\
\hline Aeroshell parachute area & $5.03 \mathrm{~m}^{2}$ & $5.28 \mathrm{~m}^{2}$ & +48 & $4.78 \mathrm{~m}^{2}$ & -37 \\
\hline Entry flightpath angle constraint & $-22.0 \mathrm{deg}$ & $-23.1 \mathrm{deg}$ & +32 & $-20.9 \mathrm{deg}$ & -165 \\
\hline
\end{tabular}

considered, the sensitivity to the value of the pullup Mach constraint is asymmetric.

The direction of the sensitivity to airplane drag coefficient requires comment. Increasing the airplane drag coefficient by 5 percent helps to limit the airspeed and Mach number buildup during the pullup maneuver. This allows the pullup maneuver to be initiated at an increased altitude where atmospheric density (and hence aerodynamic forces) is less. The increased drag coefficient compensates for the reduced density to keep the Mach number below the constraint limit, and the result is an increased $h_{A G L_{F}}$.

Increasing the total entry mass yields a net increase in altitude. The entry system with the higher mass (that is, higher ballistic coefficient) experiences lower deceleration as a result of aerodynamic drag, and it carries further downrange. The system with higher mass attains parachute deployment at a shallower $\gamma_{R}$, the pullup maneuver requires less altitude, and a higher $\mathrm{h}_{\mathrm{AGL}}$, results. Sensitivities to the remaining parametric variations are small in magnitude.

\section{Airplane-Drag Optimized Trajectory Design}

The preceding sensitivity analysis results show that increasing the drag coefficient of the airplane during the pullup maneuver yields an improvement in $h_{A G L}$. The sensitivity study results indicate the direction for performance improvement, but do not indicate the magnitude of the drag increment or the maximum performance increment that is achievable by increasing the drag coefficient. To address these issues, the original problem formulation was modified to give an airplanedrag optimized trajectory design formulation.

The physical mechanism used for adding drag to the airplane was unimportant for this design iteration. Modest amounts of drag could be added with dive brakes; larger amounts of drag could be added with a drogue parachute; both drag and lift could be added with a flapped airfoil. For this analysis, the drag increment was cast in a generic form as a drag coefficient multiplier; the magnitude of the multiplier resulting from the analysis would then suggest the physical mechanism to be implemented.

First, the original optimal control vector was augmented with the inclusion of

- Airplane drag coefficient multiplier

- Release time for the drag multiplier, relative to the start of the pullup maneuver

The second element was added to the optimal control vector to model release of the drag-producing 
mechanism partway through the pullup maneuver, and to allow POST to select the optimal release time. The objective function and the constraints remained identical to the original problem formulation.

Only the AP site was studied in this analysis. For the new problem formulation, the optimal drag coefficient multiplier was 3.02 and the optimal release point for the drag device was at a Mach number of 0.77 . For illustration purposes, this drag coefficient increment can be converted to an equivalent drogue parachute to be attached to the airplane. It is equivalent to that of a DGB parachute with a drag coefficient of 0.55 and an inflated diameter of $0.38 \mathrm{~m}$. or about 37 percent of the airplane wingspan.

Time history results for the AP site are shown in figures 19 through 23. The large drag increment has a strong impact on the whole trajectory design. The optimal $\gamma_{I R V}$, becomes much shallower, rising from $-22^{\circ}$ for the baseline trajectory design to $-17.6^{\circ}$ for the airplane-drag optimized design as shown in figure 19. The shallower entry reduces the maximum deceleration from 20 Earth $g$ to 14 Earth $g$, as shown in figure 20, and stretches the time for the EDF trajectory from $160 \mathrm{sec} 10220 \mathrm{sec}$.

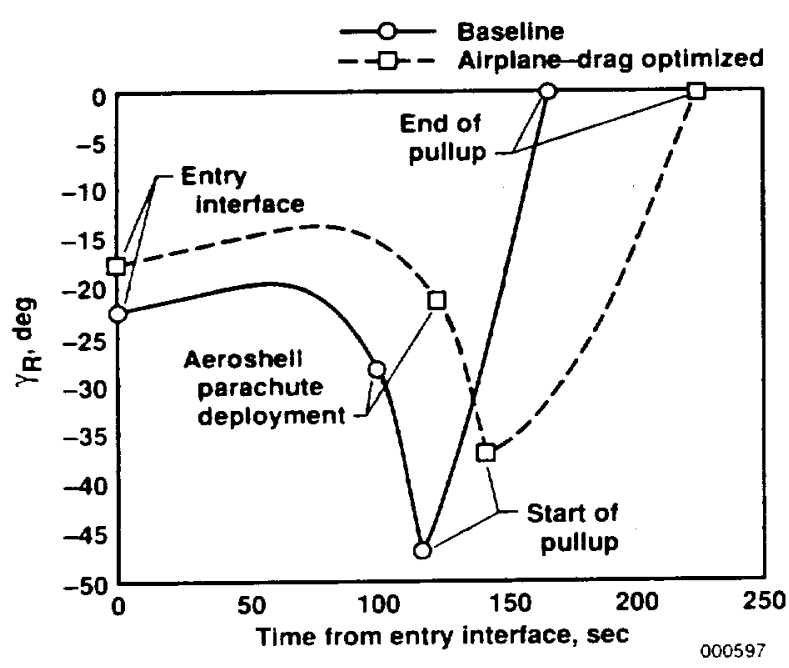

Figure 19. Comparison of time histories of $\Upsilon_{R}$ for the baseline and airplane-drag optimized trajectories for the AP mission site.
Compared to the baseline design, the airplane-drag optimized design starts at a higher $h_{A G L}$ as shown in figure 21, a higher Mach number as shown in figure 22, and a higher dynamic pressure as shown in figure 23 . Although the atmospheric density is reduced at the increased $h_{A G L}$, the additional airplane drag keeps the Mach number below the constraint limit throughout the pullup maneuver, allowing the start of the pullup maneuver to rise from an $h_{A G L}$ of $6000 \mathrm{~m}$ for the baseline design to $9400 \mathrm{~m}$ for the airplane-drag optimized design. The Mach number reaches the constraint limit twice during the pullup maneuver; once while the additional drag is present, and again after the additional drag is released. Throughout most of the pullup maneuver, the dynamic pressure is lower for the airplane-drag optimized design than for the baseline design. Consequently, the aerodynamic lift is lower, and more altitude is consumed in performing the pullup maneuver for the airplane-drag optimized design than for the baseline design. However, because the pullup maneuver is initiated at an increased altitude, $h_{A G L_{f}}$ rises from $2745 \mathrm{~m}$ for the baseline design to $4477 \mathrm{~m}$ for the airplane-drag optimized design.

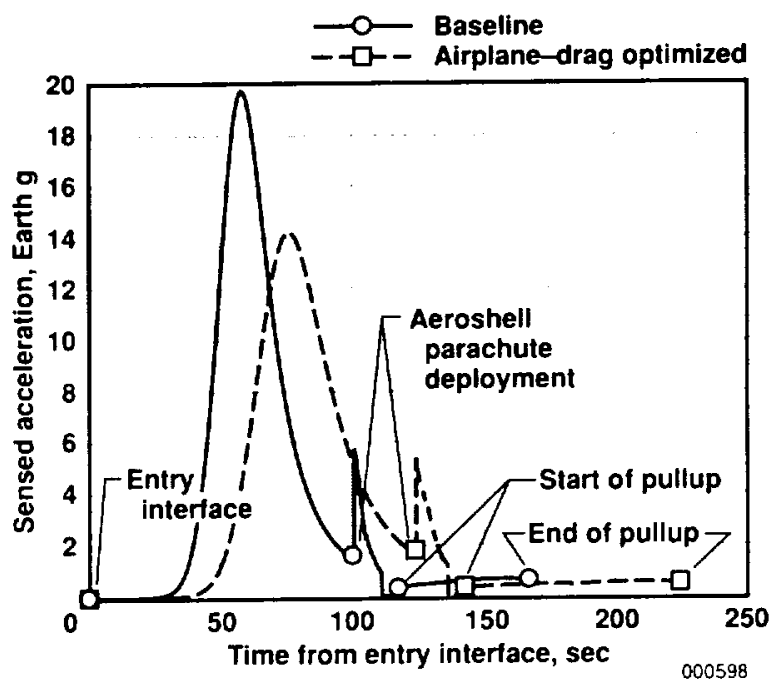

Figure 20. Comparison of time histories of acceleration for the baseline and airplane-drag optimized trajectories for the AP mission site. 


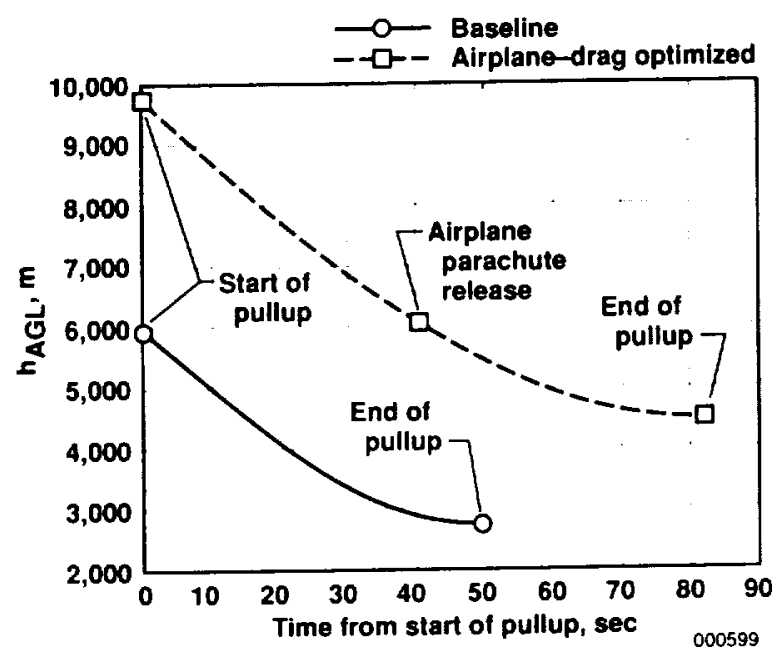

Figure 21. Comparison of time histories of $\mathrm{h}_{\mathrm{AGL}}$ for the pullup maneuver for the baseline and airplane-drag optimized trajectories for the AP mission site.

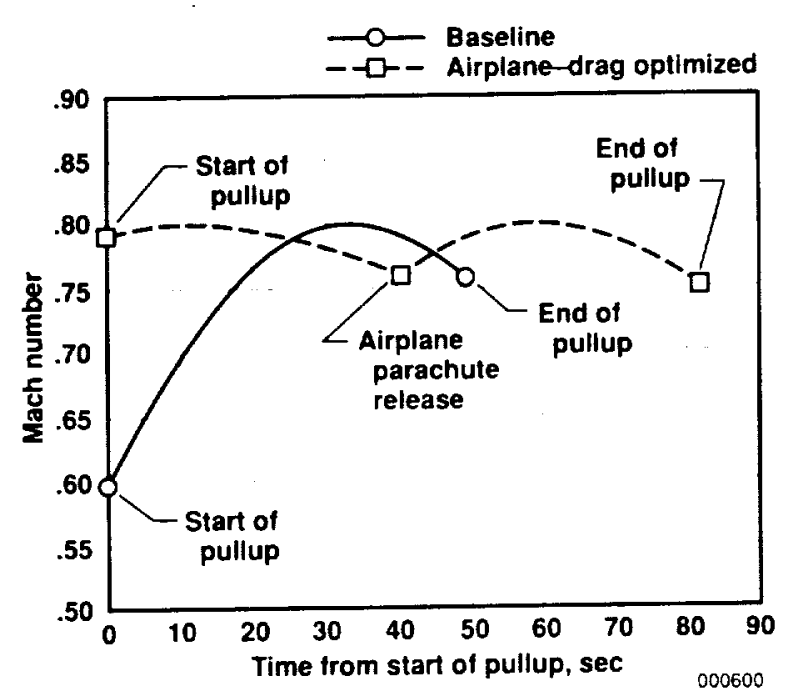

Figure 22. Comparison of time histories of Mach number for the pullup maneuver for the baseline and airplane-drag optimized trajectories for the AP mission site.

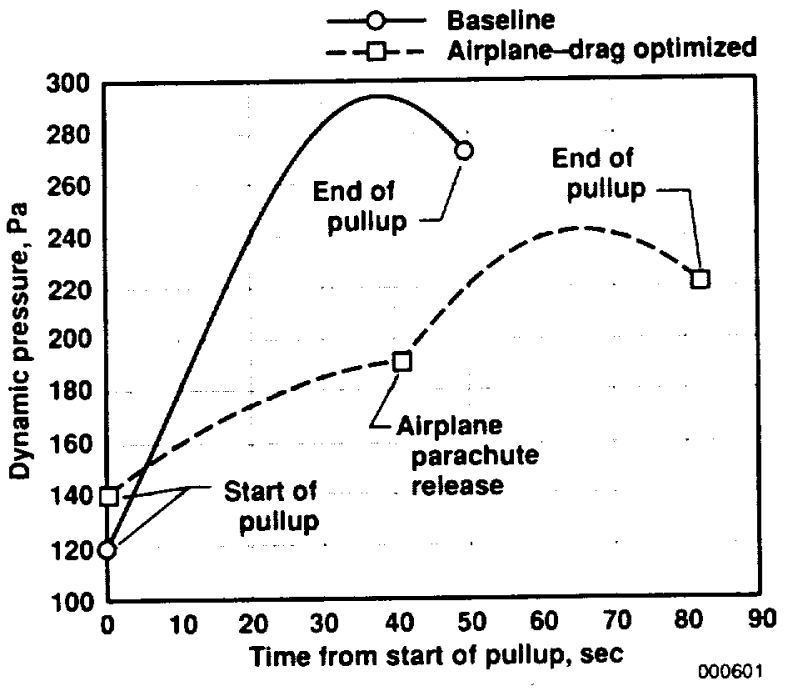

Figure 23. Comparison of time histories of dynamic pressure for the pullup maneuver for the baseline and airplane-drag optimized trajectories for the AP mission site.

\section{Conclusions}

For the trajectory optimization problem formulated, and for using the model data representative of this Mars airplane configuration, the models of the Martian surface topography and atmosphere, and the estimates of the entry state vector, the following conclusions were drawn:

1. For all sites considered, the optimal trajectories were driven to the steepest allowable entry flightpath angles. Parachute deployments occurred between 5 and 7.5 kilometers above the surface and at Mach numbers ranging from 1.7 to 1.9. The pullup maneuver required several kilometers of altitude to execute, as a result of the low available lift coefficient at the transonic, low-Reynoldsnumber flight condition.

2. The performance of the EDF trajectory is very sitesensitive for two primary reasons. The wide variation in surface topography on the planetary scale considered has a direct effect on $h_{A G L_{t}}$. Additionally, the wide variation in atmospheric conditions on the planetary scale considered results in a similarly wide variation in flight Mach number and Reynolds number, even at the same true airspeed flight condition. The aerodynamic performance of the airplane is a strong function of 
both lift and drag coefficients; hence the additional sensitivity of $h_{A G L_{f}}$ to the site considered. For the best-performing site (Acidalia Planitia), $\mathrm{h}_{\mathrm{AGL}_{\mathrm{f}}}$ was $2745 \mathrm{~m}$ above the surface; for the poorestperforming site (Parana Valles), it was impossible to complete the pullup maneuver before surface impact.

3. The sensitivity analysis showed that $\mathrm{h}_{\mathrm{AGL}}$ was most sensitive to the mass and aerodynamic characteristics of the airplane, and the pullup Mach constraint. Both decreasing the airplane mass and increasing the maximum available lift coefficient

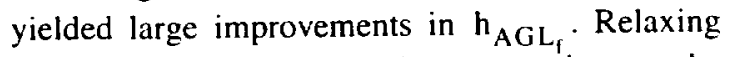
the maximum Mach number constraint on the airplane during the pullup maneuver also yielded a large improvement, while tightening this constraint by the amount studied made it impossible to execute the pullup maneuver before surface impact. Increasing the drag coefficient of the airplane during the pullup maneuver yielded a significant increase in $h_{A G L}$. The increased drag coefficient allowed the pullup maneuver to be started at an increased altitude while still maintaining the same maximum Mach number limit.

4. The airplane drag-optimized trajectory design is fundamentally different than the baseline trajectory design. For the drag-optimized trajectory the optimal entry flightpath angle is shallower, the parachute deployment occurs higher, the pullup maneuver starts at a shallower flightpath angle, and the whole trajectory takes longer to execute. The result is a significant performance improvement over the baseline design; $h_{A G L}$ rose from $2745 m$ to $4477 \mathrm{~m}$.

\section{References}

${ }^{1}$ Reed, R. Dale, "High-Flying Mini-Sniffer RPV: Mars Bound?", Astronautics and Aeronautics, vol. 16, no. 6, June 1978, pp. 26-39.

${ }^{2}$ Clarke, V. C., Jr., A. Kerem, and R. Lewis, A MARS Airplane...Oh Really?, AIAA paper 79-0067, January 1979.

${ }^{3}$ Anonymous, Study of Advanced Atmospheric Entry Systems for Mars, NASA CR-157548, July 1978.

${ }^{4}$ Colozza, Anthony J., Preliminary Design of a Long-Endurance Mars Aircraft, NASA CR-185243. April 1990.

${ }^{5}$ Anonymous, Aerospace Vehicle Design, Spacecraft Section. Volume 3, NASA CR-184743, May 1988.
${ }^{6}$ Bouras, Peter and Tim Fox, An Autonomous Flying Vehicle for Mars Exploration, AIAA paper 90-3235, September 1990.

${ }^{7}$ Hall, David W., Robert W. Parks, and Dr. Steve Morris, "Conceptual Design of the Full-Scale Vehicle Design, Construction, and Test of Performance and Deployment Models (Final Report)," May 27, 1997. David Hall Consulting, 1111 West El Camino Real, Suite 109, Sunnyvale, California, at website http://www.redpeace.org, viewed October 16, 2000 at Web page titled Visit to the Red Planet.

${ }^{8}$ Smith, S. C., A. S. Hahn, W. R. Johnson, D. J. Kinney, J. A. Pollitt, and J. R. Reuther, The Design of the Canyon Flyer, An Airplane for Mars Exploration, AIAA paper 2000-0514, January 2000.

${ }^{9}$ Brauer, G. L., D. E. Cornick, and R. Stevenson, Capabilities and Applications of the Program to Optimize Simulated Trajectories (POST). Program Summary Document, NASA CR-2770, February 1977.

${ }^{10}$ Peng, Chia-Yen, Jet Propulsion Laboratory, unpublished personal communication, May 1999.

${ }^{11}$ Penzo, Paul A., Senior Engineer, Navigation and Mission Design Section, Jet Propulsion Laboratories, unpublished personal communication, September 1999.

${ }^{12}$ Sergeyevsky, Andrew B., Gerald C. Snyder, and Ross A. Cuniff, Imerplanetary Mission Design Handbook, Volume I, Part 2: Earth to Mars Ballistic Mission Opportunities, 1990-2005, JPL Publication 82-43, September 15, 1983. NASA STI Archives, 1984.

${ }^{13}$ Knacke, Theo W., Parachute Recovery Systems Design Manual, NWC TP 6575, March 1991.

${ }^{14}$ Braun, Robert D., Richard W. Powell, F. McNeil Cheatwood, David A. Spencer, and Robert A. Mase, The Mars Surveyor 2001 Lander: A First Step Toward Precision Landing, IAF-98-Q.3.03, September 1998.

${ }^{15}$ Justus, C. G. and B. F. Jarvis, Mars Global Reference Atmospheric Model (Mars-GRAM) Version 3.8: User's Guide. NASA TM-1999-209629. May 1999.

${ }^{16}$ Fallon, Edward J. II, System Design Overien of the Mars Pathfinder Parachute Decelerator Subsystem, AIAA-97-1511, 1997.

${ }^{17}$ Batson, R. M., P. M. Bridges, and J. L. Inge, Atlas of Mars: the 1:5,000,000 Map Series, NASA SP-438, 1979. 
Pubtic reporting burden tor this collection of information is estimated to average 1 hour per response, including the time tor reviewing instructions, searching existing data sources, gathering and maintaining the data needed, and completing and reviewing the collection ol inlormation. Send comments regarding this burden estimate or any other aspect of inis collection of intormation, VA 22202-4302, and to the OHfice of Management and Budget. Paperwork Reduction Projecl (0704-0188). Washington, DC 20503

\begin{tabular}{|l|l|l}
\hline 1. AGENCY USE ONLY (Leave blank) & $\begin{array}{l}\text { 2. REPORT DATE } \\
\text { January 2001 }\end{array}$ & $\begin{array}{c}\text { 3. REPORT TYPE AND DATES COVERED } \\
\text { Technical Memorandum }\end{array}$ \\
\hline
\end{tabular}

4.TITLE AND SUBTITLE

January 2001

Development of a Mars Airplane Entry, Descent, and Flight Trajectory

6. AUTHOR(S)

WU 529-10-04-E8-29-00-MAR

James E. Murray and Paul V. Tartabini

7. PERFORMING ORGANIZATION NAME(S) AND ADDRESS(ES)

NASA Dryden Flight Research Center

P.O. Box 273

Edwards, California 93523-0273

H-2436

9. SPONSORING/MONITORING AGENCY NAME(S) AND ADDRESS(ES)

10. SPONSORING/MONITORING

AGENCY REPORT NUMBER

National Aeronautics and Space Administration

Washington, DC 20546-0001

NASA/TM-2001-209035

11. SUPPLEMENTARY NOTES

Presented at 39th AIAA Aerospace Sciences Meeting and Exhibit, Reno, Nevada, January 8-11, 2001, AIAA2001-0839. Paul V. Tartabini, NASA Langley Research Center, Hampton, Virginia.

12a. DISTRIBUTIONAVALLABILITY STATEMENT

2b. DISTRIBUTION CODE

Unclassified-Unlimited

Subject Category 91

This report is available at http://www.dfrc.nasa.gov/DTRS/

13. ABSTRACT (Maximum 200 words)

An entry, descent, and flight (EDF) trajectory profile for a Mars airplane mission is defined as consisting of the following elements: ballistic entry of an aeroshell; supersonic deployment of a decelerator parachute; subsonic release of a heatshield; release, unfolding, and orientation of an airplane to flight attitude; and execution of a pullup maneuver to achieve trimmed, horizontal flight. Using the Program to Optimize Simulated Trajectories (POST) a trajectory optimization problem was formulated. Model data representative of a specific Mars airplane configuration, current models of the Mars surface topography and atmosphere, and current estimates of the interplanetary trajectory, were incorporated into the analysis. The goal is to develop an EDF trajectory to maximize the surface-relative altitude of the airplane at the end of a pullup maneuver, while subject to the mission design constraints. The trajectory performance was evaluated for three potential mission sites and was found to be site-sensitive. The trajectory performance, examined for sensitivity to a number of design and constraint variables, was found to be most sensitive to airplane mass, aerodynamic performance characteristics, and the pullup Mach constraint. Based on the results of this sensitivity study, an airplane-drag optimized trajectory was developed that showed a significant performance improvement.

\begin{tabular}{|c|c|c|}
\hline \multicolumn{3}{|l|}{. SUBJECT TERMS } \\
\hline \multicolumn{3}{|c|}{$\begin{array}{l}\text { Aircraft design, Atmospheric entry, Flight mechanics, Mars probes, Trajectory } \\
\text { optimization }\end{array}$} \\
\hline $\begin{array}{l}\text { 17. SECURITY CLASSIFICATION } \\
\text { OF REPORT }\end{array}$ & $\begin{array}{l}\text { 18. SECURITY CLASSIFICATION } \\
\text { OF THIS PAGE }\end{array}$ & $\begin{array}{l}\text { 19. SECURITY CLASSIFICATION } \\
\text { OF ABSTRACT }\end{array}$ \\
\hline Unclassified & Unclassified & Unclassified \\
\hline
\end{tabular}

NSN 7540-01-280-5500

15. NUMBER OF PAGES

21

16. PRICE CODE

$\mathrm{A03}$

20. LMITATION OF ABSTRACT

Unlimited

Stancard Form 298 (Rev. 2-89)

Prescribed by ANSI SId Z39. 18 
National Aeronautics and

Space Administration

Code JTT

Washington, D.C. 20546-0001

SPECIAL FOURTH-CLASS RATE

POSTAGE AND FEES PAID

NASA

USA

PERMIT No G27

Official Business

Penalty for Private Use, $\$ 300$

POSTMASTER: If Undeliverable (Section 158

Postal manual) Do Not Return 